\title{
Modeling of shallow, horizontal, unsaturated, ground-based heat exchangers with consideration of dry zone formation
}

\author{
Hyunjun $\mathrm{Oh}^{1}$ and James M. Tinjum ${ }^{1 *}$ \\ ${ }^{1}$ University of Wisconsin-Madison, Department of Civil and Environmental Engineering, 53705 Madison, WI, USA
}

\begin{abstract}
High fluid temperatures in ground-based heat exchangers (GHXs) during the cooling season may result in a decrease in thermal conductivity of adjacent backfill ( $\left.\lambda_{\text {backfill }}\right)$, potentially causing degradation in the performance efficiency of the GHX system. In this study, numerical modeling was performed using the SVOffice ${ }^{\mathrm{TM}}$ finite-element software to evaluate coupled heat and moisture transfer around two GHXs. Constant-temperature boundary conditions of $35^{\circ} \mathrm{C}$ were applied to the GHX surfaces, and thermal properties of the backfill were controlled for comparisons. For estimate typical hydraulic and thermal properties for the modeling, laboratory tests and literature review were performed. Modeling results indicate that coupled heat and moisture transfer occurs rapidly near the GHX involving a dry zone formation when $\lambda_{\text {backfill }}$ decreases. A boundary between dry and wet zones where soil thermal properties rapidly change was observed around $50 \%$ GHX temperature dissipated ( $\left.\mathrm{T}_{50}\right)$, and accordingly $\mathrm{T}_{50}$ was used to optimize the pipe configuration. Coupled heat and moisture transfer increased when the GHX configurations were optimized with consideration of dry zone formation. These results imply that thermally enhanced, engineered backfill and optimized configurations can enhance GHX system efficiency.
\end{abstract}

\section{Introduction}

Ground-based heat exchangers (GHXs) in a groundsource heat pump (GSHP) system are components of cooling and/or heating units that beneficially use stored geothermal energy in the earth. Although near-surface ground temperature fluctuates due to seasonal and/or meteorological effects (typically the upper $2-5 \mathrm{~m}$ ), ground temperature becomes relatively constant at depth [1-3]. Even within this shallow subsurface zone where ground temperature varies by the season, relative to air, ground has a relatively higher temperature during winter (i.e., heat source) and a relatively lower temperature during summer (i.e., heat sink). The ground can be thus continuously used as an energy source over the entire year. Moreover, GSHP systems are cost-effective and environmentally friendly in terms of life-cycle emissions such as green-house gasses (GHG). Due to these environmental and economic benefits, GSHP systems have been widely used in many countries [4-7].

In a closed-loop GHX system, fluid (typically water or an anti-freeze solution) is circulated through buried pipes to exchange heat between the GHX and the ground. Closed-loop GHX systems are typically installed in vertical boreholes or shallow horizontal trenches. Vertical GHXs installed in boreholes have higher installation costs in comparison to horizontally trenched GHXs. However, vertical GHX systems typically have higher long-term coefficients of performance due to their interaction with more constant ground temperatures with depth. In the horizontal configuration, GHXs are installed in shallow trenches (typically $1 \mathrm{~m}$ to $5 \mathrm{~m}$ in depth). Although horizontal GHXs have lower installation costs than vertical GHX systems, performance and efficiency of horizontal GHXs can be affected by environmental conditions (e.g., precipitation and infiltration, seasonal temperature changes). This study aims to provide context to the seasonal performance of a shallow GHX in a horizontal trench in terms of coupled heat and moisture transfer in the surrounding backfill that is directly influenced by high ground loop fluid temperatures during the summer cooling season.

In addition to the environmental and meteorological impacts on performance (including system efficiency and longevity) of shallow GHXs in horizontal trenches, there are various factors that influence the performance such as the thermal and hydraulic properties of the backfill and specifications and configurations of the GHXs. Wu et al. (2015) reported that the length of a horizontal ground loop could be reduced by $25-50 \%$ when soil thermal properties are represented by realistic values and relationships (e.g., thermal conductivity dry-out curve), instead of conservative and constant soil thermal conductivity. Florides et al. (2013) also indicated that horizontal GHXs have a critical center-to-center tube distance, and there is no additional observable effect on the mean fluid temperature beyond this critical distance. In contrast to the buried electrical power cable profession, there are limited studies that investigate how dry zone formation affects coupled heat and moisture transfer around a system of GHX pipes. The objectives of this study are thus to: 1) numerically model coupled heat and moisture

\footnotetext{
* Corresponding author: imtinjum $@$ wisc.edu
} 
transfer around shallow GHX pipes installed in a horizontal trench with an operating fluid temperature of $35{ }^{\circ} \mathrm{C}$ and variable backfill properties (conservative or average thermal conductivity values (constant) versus use of a thermal conductivity dry-out curve), 2) evaluate dry zone formation around the GHX, and 3) compare and optimize the GHX configuration.

\section{Materials}

For the physical, hydraulic, and thermal properties used in the modeling, two soil samples were collected from sites in central Texas and Wisconsin. The soil samples were classified by ASTM D422 [9] and ASTM D2487 [10] as silty sand (SM) and poorly graded sand (SP), respectively, and are used as ground soil and backfill in the modeling, respectively. Fig. 1 represents the grain-size distribution curves. In addition to sieve analyses, standard Proctor tests, ASTM D698 [11], were conducted for the soil samples to measure maximum dry unit weight $\left(\gamma_{\text {dmax }}\right)$, which was used as a model parameter. Table 1 summarizes index properties-soil particle diameters corresponding to $10 \%$ and $50 \%$ finer $\left(D_{10}\right)$ and $\left(D_{50}\right)$, respectively; coefficient of uniformity $\left(C_{u}\right)$; and coefficient of curvature $\left(C_{c}\right)$ - and $\gamma_{d \max }$.

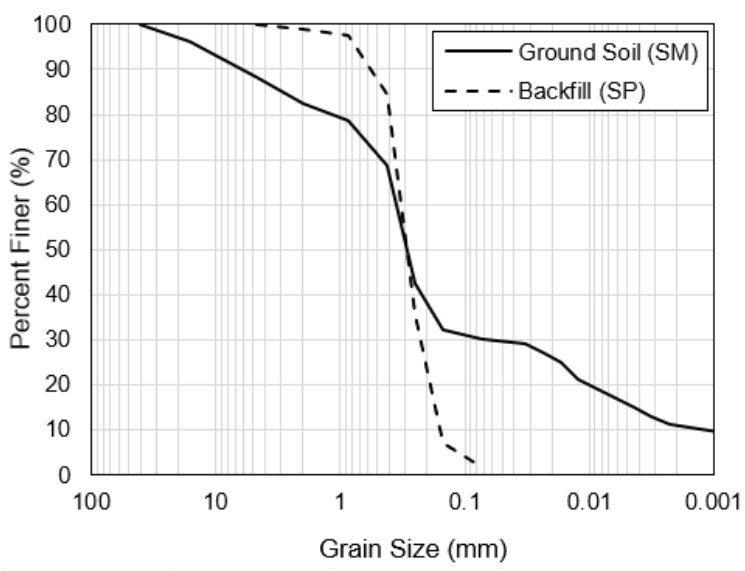

Fig. 1. Grain-size distribution curves.

Table 1. Index and Physical Properties of Two Soil Samples.

\begin{tabular}{|c|c|c|c|c|c|c|}
\hline Sample & $\begin{array}{c}D_{10} \\
(\mathrm{~mm})\end{array}$ & $\begin{array}{c}D_{50} \\
(\mathbf{m m})\end{array}$ & $\begin{array}{c}\text { Fines } \\
(\%)\end{array}$ & $C_{u}$ & $C_{c}$ & $\begin{array}{c}\gamma_{\max x} \\
\left(\mathbf{k N} / \mathrm{m}^{3}\right)\end{array}$ \\
\hline $\begin{array}{l}\text { Ground } \\
\text { (SM) }\end{array}$ & 0.001 & 0.299 & 30.22 & 368 & 12.2 & 16.44 \\
\hline $\begin{array}{l}\text { Backfill } \\
\text { (SP) }\end{array}$ & 0.175 & 99 & 1.75 & 1.85 & 0.88 & 17.89 \\
\hline
\end{tabular}

Coupled heat and moisture transfer in soil (e.g., dry zone formation) depends on the hydraulic and thermal properties of the soil [12]. The hydraulic and thermal behaviors of unsaturated soil can be predicted using the soil-water characteristic curve (SWCC), which is a relationship between matric suction and degree of saturation, and the thermal conductivity dry-out curve (TCDC) that represents thermal conductivity $(\lambda)$ at variously saturated conditions $[8,13-16]$. In this study, SWCCs and TCDCs of the two soil samples were experimentally measured using the multiple-specimen testing method [17] and modified Tempe cell testing, which have been widely used in the literature [16-17]. In the multiple specimen tests, thermal conductivity of the soil was measured under various conditions (e.g., 3\% moisture content compacted to $90 \% \gamma_{\text {dmax }}$ ). Based on the soil properties in Table 1 and SWCCs and TCDCs obtained from testing and the literature [15-19], SWCCs and TCDCs were validated and calibrated to represent typical hydraulic and thermal properties of unsaturated soil at a field site and to reduce computational time. The SWCCs and TCDCs used in the modeling are presented in Fig. 2. As degree of saturation decreases, matric suction increases while thermal conductivity decreases, especially below the critical degree of saturation; i.e., the point where liquid bridges among particles break down. Below this critical degree of saturation, soil hydraulic and thermal properties can greatly fluctuate.

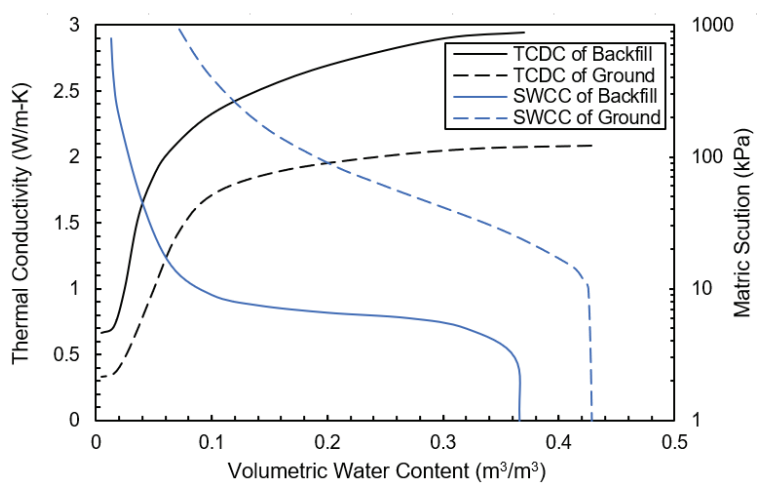

Fig. 2. Soil-water characteristic curves and thermal conductivity dry-out curves used for material properties in the modeling.

\section{Coupled Heat and Moisture Transfer Modeling of GHXs}

In two-dimensional (2D) modeling of a horizontal GHX system, a mid-section of the system is simulated to approximate and represent the whole system. Although there are potential limitations, such as modeling change in performance over the system based on changes in soil thermal conductivity (especially when the system is exceptionally long), previous studies, such as [8], [20], and [21], have indicated that the $2 \mathrm{D}$ modeling provides reasonable results with the benefit of reduced computational time. Accordingly, in this study, coupled heat and moisture transfer around a single GHX pipe was modeled in two-dimensions using SVHeat and SVFlux in the SVOffice $^{\mathrm{TM}}$ finite-element software package (SoilVision Systems Ltd.). Equation 1 shows the governing equation for moisture migration driven by pore water pressure and temperature gradients in terms of hydraulic and vapor conductivities. The second governing equation (equation 2) models heat transfer caused by conduction, convection, and latent heat of fusion of water. 


$$
\begin{gathered}
\frac{\partial}{\partial y}\left[k_{11} \frac{\partial u_{w}}{\partial y}+k_{y}^{w}+k_{12} \frac{\partial T}{\partial y}\right]=\frac{\partial \theta_{u}}{\partial t}+\frac{\rho_{i}}{\rho_{w}} \frac{\partial \theta_{i}}{\partial t} \\
k_{11}=\frac{k_{y}^{w}+k^{v d}}{\gamma_{w}}, k_{12}=\frac{k^{v d}\left(-u_{w}\right)}{\gamma_{w}(274.15+T)}, k^{v d}=\gamma_{w} \frac{w_{v} u_{v}^{\text {soil }}}{\rho_{w} R(T+273.15)} \frac{D^{v *}}{\rho_{w}} \\
\frac{\partial}{\partial y}\left(k_{21} \frac{\partial u_{w}}{\partial y}+k_{22} \frac{\partial T}{\partial y}+L_{f} k_{y}^{w}\right)-C_{w} q_{y}^{w} \frac{\partial T}{\partial y} \\
=\left(C+L_{f} m_{2}^{i}\right) \frac{\partial T}{\partial t} \\
k_{21}=\frac{\left(L_{f} k_{y}^{w}+L_{v} k^{v d}\right)}{\gamma_{w}}, k_{22}=\lambda_{y}+\left(L_{v}+L_{f}\right) k_{12}
\end{gathered}
$$

where $k_{y}^{w}$ is hydraulic conductivity, $k^{v d}$ is vapor conductivity by diffusion, $w_{v}$ is molecular weight of vapor $\left(0.018016 \mathrm{~kg} \cdot \mathrm{mol}^{-1}\right), u_{w}$ is pore water pressure due to hydraulic head, $R$ is universal gas constant $(9.314$ $\left.\mathrm{J} \cdot \mathrm{molK}^{-1}\right), D^{v *}$ is vapor diffusivity, $T$ is temperature, $u_{v}^{\text {soil }}$ is soil-water vapor pressure, $\gamma_{w}$ is unit weight of water, $\theta_{u}$ is volumetric water content, $\theta_{i}$ is volumetric ice content, $\rho_{w}$ is water density, $\rho_{i}$ is ice density, $y$ is elevation, $t$ is time, $\lambda_{y}$ is thermal conductivity, $L_{v}$ is volumetric latent heat of water vaporization or condensation, $C_{w}$ is volumetric heat capacity of water, $q_{y}^{w}$ is water flow flux, $C$ is volumetric heat capacity of soil, $L_{f}$ is volumetric latent heat of fusion of water, and $m_{2}^{i}$ is slope of the soilfreezing characteristic curve, $S F C C$, which is a relationship between freezing soil temperature (or suction) and unfrozen water content.

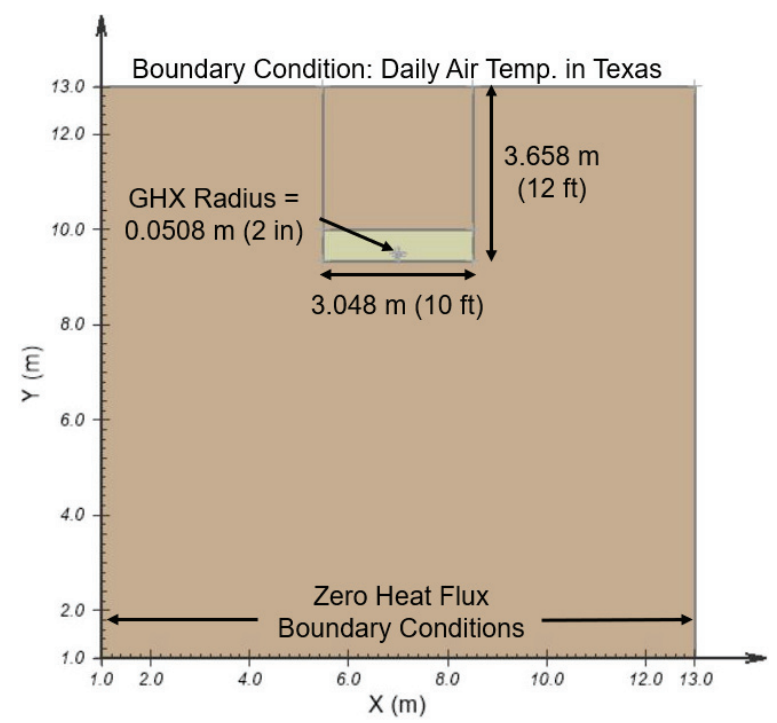

Fig. 3. Geometry and boundary conditions of the model domain.

The model domain had 12-m width and 12-m depth to sufficiently observe heat and moisture transfer from the GHX (Fig. 3). A horizontal trench of 3.048-m width was installed $3.658 \mathrm{~m}$ from the top surface. A single GHX (diameter $=10 \mathrm{~cm}$ ) was centrally placed on the bottom of the trench, and engineered backfill (3.048-m width and $0.66-\mathrm{m}$ height) was incorporated to induce heat transfer from the GHX. Initial gravimetric water contents of the ground and backfill were assigned as $27 \%$ and $22 \%$, respectively. Physical, hydraulic, and thermal properties of SP were assigned for material properties of the backfill domain, and those of SM were used for the ground domain. In addition to the TCDCs for soil thermal properties, constant $\lambda$ values were used to represent conservative and average thermal properties of the ground and backfill soils: 1) $\lambda_{\text {conservative }}=0.3 \mathrm{~W} / \mathrm{m} \cdot \mathrm{K}$ and 0.45 $\mathrm{W} / \mathrm{m} \cdot \mathrm{K}$ for ground and backfill, respectively; and 2 ) $\lambda_{\text {average }}=0.86 \mathrm{~W} / \mathrm{m} \cdot \mathrm{K}$ and $1.2 \mathrm{~W} / \mathrm{m} \cdot \mathrm{K}$ for ground and backfill, respectively.

In this study, complexity of computational fluid dynamics (CFD) for modeling fluid temperature was simplified as a constant temperature of $35^{\circ} \mathrm{C}$, and this temperature was applied to the GHX surface to evaluate how a thermal gradient induces heat and moisture transfer. Zero-flux boundary conditions were used on the left and right sides of the domain. Twelve years of air temperature data was collected from a regional airport in central Texas, and the average daily temperature was assigned on the top surface as the upper boundary condition (Fig. 4). Initial ground temperature at any depth, $\mathrm{y}$, was also modeled using a pure harmonic function as follows [1]:

$$
\begin{aligned}
T_{g}(y, t) & =T_{a}+A_{0} e^{(y / \sqrt{2 \alpha / \omega})} \\
& \sin \left[\frac{2 \pi\left(t-t_{0}\right)}{365}-\frac{y}{\sqrt{2 \alpha / \omega}}-\frac{\pi}{2}\right]
\end{aligned}
$$

where $T_{a}$ is average ground temperature, $A_{0}$ is annual amplitude of the ground temperature, $y$ is depth, $\alpha$ is soil thermal diffusivity, $\omega$ is annual angular frequency, $t$ is time, $t_{0}$ is time lag from an arbitrary starting date (usually January 1) to the occurrence of the minimum temperature in year.

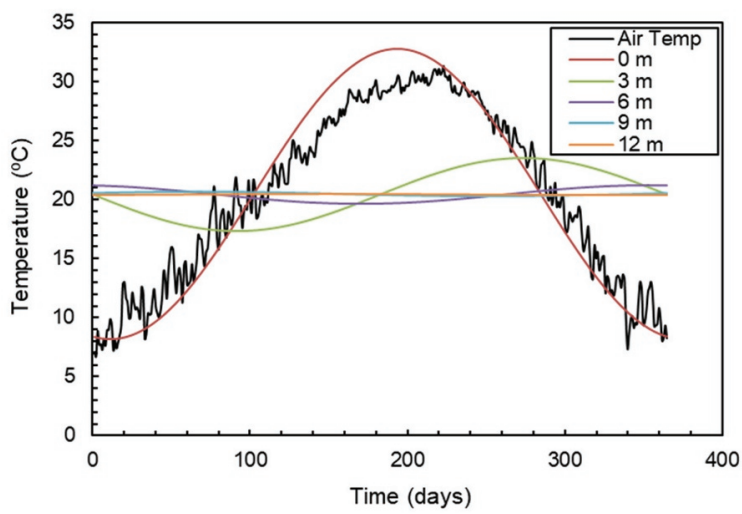

Fig. 4. Average daily air temperature data in Texas and ground temperature at various depths.

\section{Results}

Fig. 5 presents coupled heat and moisture transfer in the soil domain under GHX temperature of $35^{\circ} \mathrm{C}$ after 258 days (mid-September) from the start of the year (i.e., January $1^{\text {st }}$ ). Heat fluxes are represented with vectors in 
Fig. 5(b). As ground temperature increased from the top surface (ground temperature at the $258^{\text {th }}$ day $=26.8^{\circ} \mathrm{C}$ ) and from heat emanating from the GHX, rapid heat transfer was observed, particularly near the GHX [orange arrows in Fig. 5(b)]. This heat transfer is due to high temperature gradient which, in turn, results in a significant decrease in volumetric water content (VWC) in the domain (note that the reduced VWC subsequently causes a decrease in the thermal conductivity). For example, Fig. 5(b) shows that the entire backfill domain had the lowest VWC (e.g., dry soil) due to this rapid heat transfer through the backfill that originally has higher thermal conductivity. The decreased VWC indicates that soil thermal conductivity decreases approximately from 2.5 $\mathrm{W} / \mathrm{m} \cdot \mathrm{K}$ to $0.7 \mathrm{~W} / \mathrm{m} \cdot \mathrm{K}$, as described in Fig. 2, potentially resulting in a decrease in the GHX efficiency.



(a)

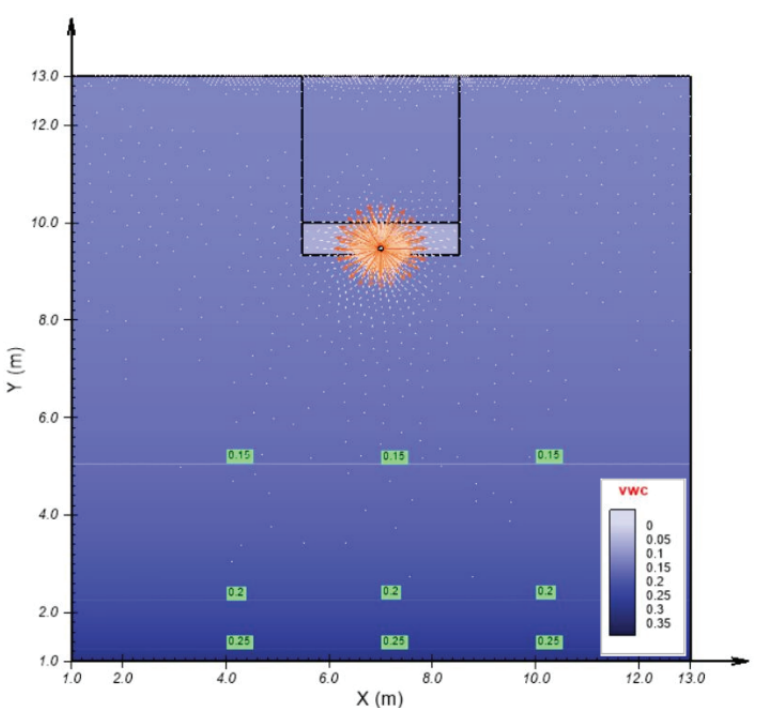

(b)

Fig. 5. Modeling results of $35^{\circ} \mathrm{C} \mathrm{GHX}$ temperature case after 258 days (mid-September): (a) temperature variation and (b) volumetric water content (VWC) with heat flux (arrows).
According to [12], soil thermal behavior significantly changed near a boundary between dry and wet zones. Specifically, heat transfer gradually occurred through wet soil that has a relatively higher thermal conductivity while rapid heat transfer was observed in dry soil near the GHX due to a relatively lower thermal conductivity. Gravimetric moisture content near the boundary was about $1 \%$. In this study, physical properties of the backfill were adapted from one sample used in [12], and modeling results indicated similarly that VWC around a boundary between dry and wet zones is about $0.04 \mathrm{~m}^{3} / \mathrm{m}^{3}$, which is about $1 \%$ gravimetric moisture content. In contrast to the rapid heat and moisture transfer around the GHX, more gradual gradients of temperature and VWC were observed at distance from the GHX. In other words, moist soil far from the GHX helped with heat dissipation through both liquid and solid elements while dry soil near the GHX performed as an insulator that holds the heat.

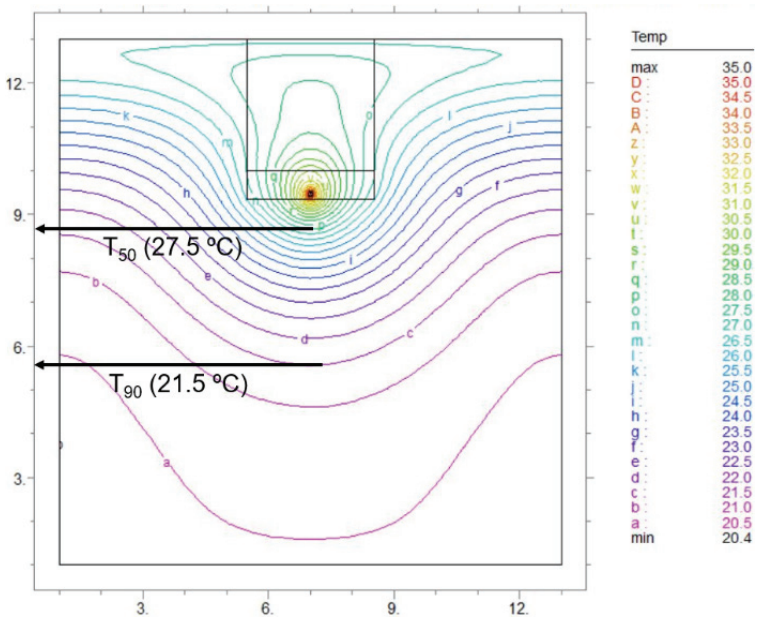

Fig. 6. Isotherms of $35^{\circ} \mathrm{C}$ GHX temperature case after 258 days (mid-September) with $\mathrm{T}_{50}$ and $\mathrm{T}_{90}$.

Fig. 6 also shows isotherms for the same case (GHX temperature of $35{ }^{\circ} \mathrm{C}$ after 258 days) to more precisely quantify heat dissipation from the GHX. Oh and Tinjum (2017) reported that a boundary between dry and wet zones is observed where the heater temperature of about $30 \%$ to $50 \%$ dissipated (depending soil thermal properties). Similarly, in this modeling, the isotherm where $50 \%$ of the delta between pipe temperature and undisturbed ground temperature was dissipated (i.e., $\mathrm{T}_{50}$ ) approximately indicated the boundary between moist and dry soils (i.e., $27.5^{\circ} \mathrm{C}$ isotherm in Fig. 6). That is, the soil inside $\mathrm{T}_{50}$ has a dry condition where soil thermal conductivity significantly decreases while the soil outside $\mathrm{T}_{50}$ is moist where heat transfer smoothly occurs due to the higher thermal conductivity. However, as described above, the boundary between dry and moist zones is dependent on soil physical properties [12], and thus, to apply this $\mathrm{T}_{50}$ approach to different soil types, evaluation of soil critical temperature-where moisture outflow under a thermal gradient is balanced by the countering inflow induced by the suction gradient (i.e., a boundary between dry and wet zones) - is necessary. In addition to $\mathrm{T}_{50}, 90 \%$ GHX temperature dissipation $\left(\mathrm{T}_{90}\right)$ was 
investigated to compare how far it takes to dissipate the bulk of the heat from the GHX under various conditions. In Fig. 6, distances from the GHX were $0.745 \mathrm{~m}$ and 3.834 $\mathrm{m}$ for $\mathrm{T}_{50}$ and $\mathrm{T}_{90}$, respectively.

Table 2. Summary of $\mathrm{T}_{50}$ and $\mathrm{T}_{90}$ under various conditions.

\begin{tabular}{|c|c|c|}
\hline \multirow{2}{*}{$\begin{array}{c}\text { Thermal } \\
\text { Property }\end{array}$} & \multicolumn{2}{|c|}{ Distance from bottom of GHX (m) } \\
\cline { 2 - 3 } & $\mathbf{T}_{\mathbf{5 0}}$ & $\mathbf{T}_{\mathbf{9 0}}$ \\
\hline TCDC & 0.745 & 3.834 \\
\hline$\lambda_{\text {average }}$ & 0.577 & 3.285 \\
\hline$\lambda_{\text {conservative }}$ & 0.398 & 2.175 \\
\hline
\end{tabular}

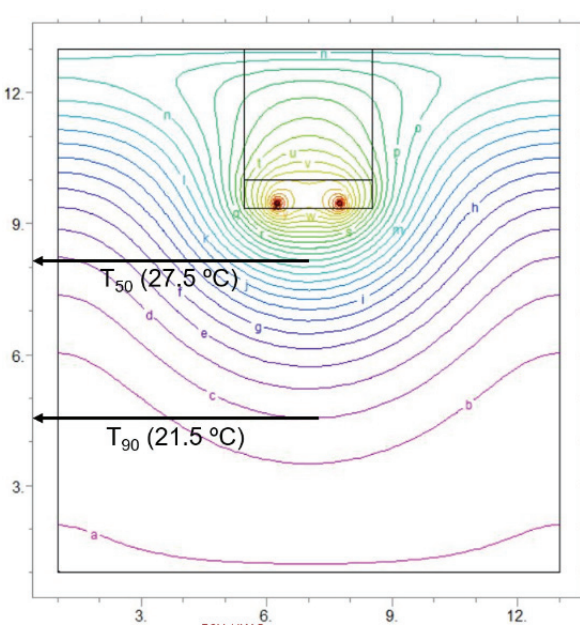

(a)

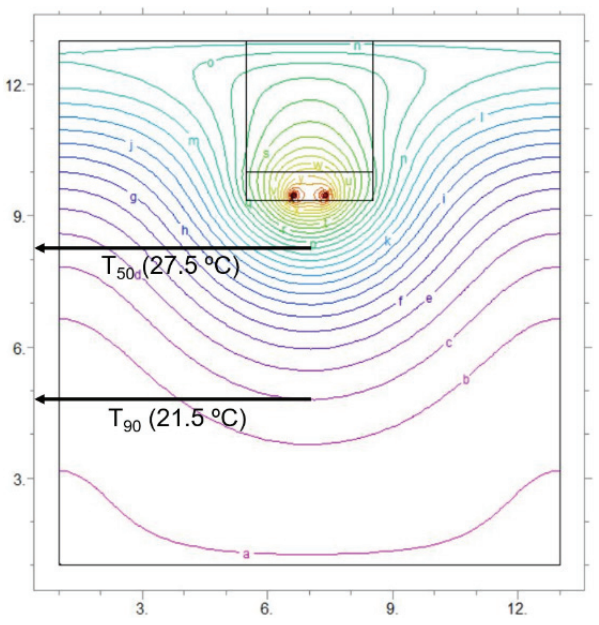

(b)

Fig. 7. Isotherms of two GHXs $\left(35^{\circ} \mathrm{C}\right.$ GHX temperature after 258 days) with $\mathrm{T}_{50}$ and $\mathrm{T}_{90}$ : (a) GHX spacing of $1.5 \mathrm{~m}$ with consideration of dry zone formation and (b) GHX spacing of $0.75 \mathrm{~m}$ without consideration of dry zone formation.

Table 2 summarizes $\mathrm{T}_{50}$ and $\mathrm{T}_{90}$ under various thermal properties (TCDC, $\lambda_{\text {conservative, and }} \lambda_{\text {average }}$ ). As the thermal conductivity increased (i.e., from $\lambda_{\text {conservative }}$ to TCDC or $\lambda_{\text {average }}$ ), heat dissipation from the GHX actively occurred over a wider area as demonstrated by increases in both $\mathrm{T}_{50}$ and $\mathrm{T}_{90}$. Although the dry zone size $\left(\mathrm{T}_{50}\right)$ also increased through continued heat transfer, these findings indicate that there was no significant impact of this increased dry zone size on GHX efficiency. That is, a decrease in thermal conductivity based on dry zone formation (see TCDCs in Fig. 2) was less important than an increase in soil thermal conductivity itself. The most realistic and accurate heat transfer was modeled when the soil thermal conductivity was assigned from the TCDC relationship.

Fig. 7 presents isothermal contour lines of two GHXs $\left(35{ }^{\circ} \mathrm{C}\right.$ GHX temperature after 258 days) with two different GHX pipe spacings $(1.5 \mathrm{~m}$ and $0.75 \mathrm{~m})$. With decrease in pipe spacing from $1.5 \mathrm{~m}$ to $0.75 \mathrm{~m}(50 \%$ reduction), $\mathrm{T}_{50}$ and $\mathrm{T}_{90}$ decreased from $1.259 \mathrm{~m}$ to 1.151 $\mathrm{m}$ and from $4.873 \mathrm{~m}$ to $4.623 \mathrm{~m}$, respectively. Optimized piping configuration [Fig. 7(a)] provides better performance and efficiency in terms of effective heat exchange between the GHX pipes and the soil.

\section{Summary and Conclusions}

In this study, coupled heat and moisture transfer around GHX pipes in a shallow horizontal trench was modeled to evaluate how thermal properties of the backfill and dry zone formation affect performance efficiency of a GHX system. As soil thermal conductivity increased, coupled heat and moisture transfer occurs more rapidly. Despite the formation of a dry zone around the GHX pipes due to this rapid heat and moisture transfer, the efficiency of heat exchange between the GHX piping and soil was improved with the increased thermal conductivity. Two different configurations of GHX piping were compared to evaluate the impact of dry zone formation $\left(\mathrm{T}_{50}\right)$ on overall system performance. Study results show that GHX pipe spacing can be optimized to enable more effective, coupled heat and moisture transfer. These results provide fundamental information of the potential for optimizing GHX systems based on the potential for and reality of dry zone formation under long, unbalanced summer cooling seasons. Future studies will systematically explore coupled heat and moisture transfer around GHXs under additional variables (e.g., size, number, spacing, depth, and operating fluid temperatures of GHXs), as well as a quantitative evaluation of performance and efficiency of the GHX system with optimized GHX configurations.

This material is based upon work supported by the Army Contracting Command-Warren under Contract W56HZV-18C-0070.

\section{References}

1. D. Hillel, Introduction to soil physics (Academic Press, New York, 1982)

2. T. P. Chacko and G. Renuka, "Temperature mapping, thermal diffusivity and subsoil heat flux at Kariavattom of Kerala,” J. Earth Syst. Sci., 111, 1, 79-85 (2002)

3. G. Florides and S. Kalogirou, "Ground heat exchangers-A review of systems, models and applications," Renew. Energy, 32, 15, 2461-2478 (2007) 
4. M. İnallı and H. Esen, "Experimental thermal performance evaluation of a horizontal groundsource heat pump system," Appl. Therm. Eng., 24, 14-15, 2219-2232 (2004)

5. H. Fujii, K. Nishi, Y. Komaniwa, and N. Chou. "Numerical modeling of slinky-coil horizontal ground heat exchangers," Geothermics, 41, 55-62 (2012)

6. G. Florides, P. Christodoulides, and P. Pouloupatis, "Single and double U-tube ground heat exchangers in multiple-layer substrates," Appl. Energy, 102, 364373 (2013)

7. N. Naili, M. Hazami, I. Attar, and A. Farhat, "In-field performance analysis of ground source cooling system with horizontal ground heat exchanger in Tunisia," Energy, 61, 319-331 (2013)

8. R. Wu, J. M. Tinjum, and W. J. Likos, "Coupled thermal conductivity dryout curve and soil-water characteristic curve in modeling of shallow horizontal geothermal ground loops," Geotech. Geol. Eng., 33, 2, 193-205, (2015)

9. "Standard test method for particle-size analysis of soils," ASTM Standard D 422-63, (2007)

10. "Standard practice for classification of soils for engineering purposes (unified soil classification system)," ASTM Standard D 2487-11, (2011)

11. "Standard test methods for laboratory compaction characteristics of soil using standard effort," ASTM Standard D 698-12, (2012)

12. H. Oh and J. M. Tinjum, "Comparison of two laboratory methods for measuring the critical temperature of sandy soils," Geotechnical Frontiers 2017, 809-817 (2017)

13. D. G. Fredlund, A. Xing, and S. Huang, "Predicting the permeability function for unsaturated soils using the soil-water characteristic curve," Can. Geotech. J., 31, 4, 533-546 (1994)

14. D. G. Fredlund, A. Xing, M. D. Fredlund, and S. L. Barbour, "The relationship of the unsaturated soil shear strength to the soil-water characteristic curve," Can. Geotech. J., 33, 3, 440-448 (1996)

15. J. M. Tinjum, C. H. Benson, and L. R. Blotz, "SoilWater Characteristic Curves for Compacted Clays," J. Geotech. Geoenviron. Eng., 123, 11, 10601069 (1997)

16. K. M. Smits, T. Sakaki, A. Limsuwat, and T. H. Illangasekare, "Thermal conductivity of sands under varying moisture and porosity in drainage-wetting cycles," Vadose Zone J., 9, 1, 1-9 (2010)

17. J. Yao, H. Oh, W. J. Likos, and J. M. Tinjum, "Three laboratory methods for measuring thermal resistivity dryout curves of coarse-grained soils," Geotech. Test. J., 37, 6, 1056-1067 (2014)

18. "IEEE guide for soil thermal resistivity measurements," IEEE Standard 442, (1981)

19. N. Lu and W. J. Likos, Unsaturated soil mechanics (Wiley, New York, 2004)
20. A. Beazza, E. Blanco, M. Aichouba, J. L. Río, and S. Laouedj, "Numerical Investigation of Horizontal Ground Coupled Heat Exchanger," Energy Procedia, 6, 29-35 (2011)

21. F. Loveridge and W. Powrie, "2D thermal resistance of pile heat exchangers," Geothermics, 50, 122-135 (2014) 